\title{
Emilio Betti e a herança idealista*
}

\author{
Hans-Georg Gadamer
}

No texto ora traduzido para o português, Gadamer sintetiza os aspectos centrais do debate que travou com Emilio Betti (1890-1968), jurista italiano e professor de direito nas universidades de Parma, Roma e Camerino. Mas que debate seria esse a reunir um filósofo, aluno de Heidegger, e um jurista que, não obstante ter estudado filosofia, passou a maior parte da vida ensinando teoria do direito e direito romano? O que estariam debatendo teóricos cujas formações parecem apontar para problemas e interesses à primeira vista tão distantes?

A hermenêutica era o elo entre ambos. O mesmo problema hermenêutico apresentavase tanto na filosofia quanto no direito. Por um lado, ao postular que o nexo histórico deve ser entendido como nexo de sentido e tratado como um grande texto estranho que a hermenêutica deve ajudar a decifrar, Dilthey "fez soar" - nas palavras de Gadamer - "a hora filosófica da hermenêutica”1; por outro lado, os juristas desenvolveram, desde há muito, uma hermenêutica voltada para suprir as lacunas e a plurivocidade de sentido do direito posto.

Se o problema era comum a filósofos e juristas, a Gadamer e Betti, os pressupostos teóricos de que se valeram para enfrentá-lo não eram. Disso resultou um profícuo debate iniciado já no começo dos anos 60 que culminou neste texto de Gadamer, publicado pela primeira vez em um livro de homenagem a Emilio Betti pelo décimo aniversário de sua morte.

Ninguém pode saltar sobre sua sombra. Isso vale tanto quando tomo a palavra para discorrer sobre Emilio Betti e lhe prestar homenagem, como valia para Emilio Betti, que insistia em ver somente erros graves em Heidegger, em Bultmann e em mim mesmo. Naturalmente eu lamentava que ele não quisesse admitir o que tínhamos em comum e o que existia de comum no trabalho que partilhávamos.

* Publicado pela primeira vez em Quaderni Fiorentini per la storia del pensiero giuridico moderno. Milão, Giuffrè Editore, 1978, nº 7. Mais tarde, como posfácio do livro de Emilio Betti Zur Grundlegung einer allgemeinen Auslegungslehre. Tübingen, J.C. Mohr, 1988. Tradução de Soraya Dib Abdul-Nour (doutoranda do Departamento de Direito Internacional da Universidade de São Paulo e bolsista FAPESP) e Leonel Cesarino Pessôa (doutorando do Departamento de Filosofia e Teoria Geral do Direito da Universidade de São Paulo). Introdução e notas de Leonel Cesarino Pessôa. Revisão de Marcio Sattin (mestrando do Departamento de Filosofia da Universidade de São Paulo). 
Nisso não estava em jogo qualquer má vontade pessoal. Eu bem me recordo daquela conferência em Heidelberg, quando ele, a meu convite, falou em meu seminário. A tensão e a excitação com que se apresentou eram inconfundíveis, mas não havia aí nem hostilidade nem tampouco a tolerância que ele próprio estimava tanto. Com certeza ele esperava me convencer. Contudo, isso quase não era necessário. Aquilo que ele combatia não era nada em que eu pudesse me reconhecer de algum modo. Eu estimava e prezava nele um homem de todo admirável, um historiador do direito respeitado internacionalmente, que ao mesmo tempo era, como talvez nenhum outro, um herdeiro fiel e defensor entusiástico da filosofia do idealismo alemão. Li seu "manifesto hermenêutico" de 1954, naquela época, com admiração, quase como uma lembrança do que estava permanentemente diante dos meus próprios olhos na tradição de minha origem. Ah não, eu não subestimava a dívida de gratidão para com o idealismo sob a qual todos nós hoje nos encontramos. Nós todos - isso inclui Heidegger, Bultmann e também Emilio Betti. No fundo, a situação problemática alemã também não era, para nós, de modo algum diferente daquela diante da qual Emilio Betti se viu posto quando procurou se libertar da influência dominante de Benedetto Croce.

Ele próprio deve ter percebido algo semelhante, apesar de nós naturalmente falarmos línguas diferentes e conversarmos sem nos entender. Em todo caso, sua visita foi muito agradável. Convidou-me insistentemente para visitá-lo em sua terra. Provavelmente esperava mesmo de mim que eu pudesse aprender a saltar sobre minha sombra.

Mas eu não via absolutamente para onde deveria saltar. Para mim, a desvalorização, levada a efeito por Croce, da objetividade nas Naturwissenschaften para a mera "Praktik", e a teoria global da expressão criadora, que ele tinha desenvolvido a partir do hegelianismo, não eram, como para Betti, uma pressão que pesasse. Que o esforço pela objetividade defina apenas em sentido limitado o procedimento da ciência era para mim algo evidente. Também a problemática do relativismo histórico, a qual ocupou sem cessar Dilthey e Troeltsch, não tinha nada de ameaçador para alguém que vivenciou em Heidegger a superação concreta do historicismo através da força do pensamento. Eu não considerava mais necessária a guinada falaciosa para um objetivismo "realista".

Oh, eu bem compreendia o que o movia. Ele sentia, como todos nós, todo o ímpeto da história e de nossa própria historicidade, procurando então escapar às conseqüências relativistas aí iminentes. Aquilo que não nos dera 
sossego nos anos depois da Primeira Guerra Mundial deve ter adquirido para ele uma nova urgência na era fascista e após seu fim. Além disso, o drama da ciência contemporânea do direito e de sua acomodação ao poder era para ele, certamente, um estímulo constante para se afastar. Infelizmente, não se orientou a esse respeito pelos mais novos desenvolvimentos do pensamento filosófico, mas por aquela espécie de realismo fenomenológico que Max Scheler e Nicolai Hartmann haviam extraído da leitura do primeiro Husserl. Assim, Heidegger lhe pareceu uma recaída no historicismo, enquanto minha própria continuidade do pensamento heideggeriano e também, particularmente, minha tentativa de afastar-me da grande tradição hermenêutica e da filosofia da história do idealismo alemão de Schleiermacher até Dilthey lhe pareceram um empreendimento arriscado. Na verdade, eu seria o último a negar que todos nós ainda nos encontramos à sombra de Hegel. No entanto, quem estaria pronto a se reconhecer totalmente na crença na razão de Hegel? Cem anos de crítica à consciência de si, tal como ela foi levada adiante por Marx e Nietzsche, por Freud e Heidegger, não podem ser apagados. A penumbra de Croce e a emancipação realizada por Emilio Betti acrescentam pouca coisa a essa discussão.

Betti me pareceu ter visto a tarefa corretamente. Seu problema mais próprio foi defender a intrínseca ação recíproca entre o interesse da história do direito e o da dogmática jurídica. Mas sua ingenuidade quanto à teoria do conhecimento fez com que incorresse em um flagrante psicologismo, quando concebeu o ato de entender como o processo inverso do ato de criar ${ }^{2}$. Isso não estava de acordo com sua compreensão, de resto correta, da ratio legis. Aqui se torna evidente a pouca convicção com que ele seguiu a tradição do idealismo alemão. Pois a correspondência entre criar e pensar teve no idealismo especulativo da filosofia da identidade seu fundamento. Foi somente a atuação de Schleiermacher na psicologia, mas não o seu idealismo especulativo, que inspirou Emilio Betti. Eu mesmo faltei um pouco com o devido cuidado na minha crítica a Schleiermacher. Não levei suficientemente em conta a circunstância de que a hermenêutica de Schleiermacher era seguida de sua "dialética” e de que aí a interdependência especulativa entre pensar e falar e a relação de verdade que orienta o pensamento formavam o tema explícito. No entanto, a separação artificial de Schleiermacher entre a apresentação hermenêutica do problema e uma dialética dirigida ao conhecimento permanece a meu ver insatisfatória. 
Muito mais insatisfatório para mim, contudo, foi como Betti montou sua doutrina dos tipos da interpretação ${ }^{3}$. Nela ele apresentou a assim chamada interpretação científica por si mesma e separou-a completamente tanto do emprego reprodutivo como do prático. Em vez de acentuar primeiramente o momento cognitivo, seja no artista - que reproduz -, seja no juiz ou no teólogo (Seelsorger) - que praticam -, e apenas então introduzir como condição restritiva a realização através da ação criadora, a questão acabou por se inverter completamente para ele. O objetivismo ingênuo com o qual procurou distinguir a interpretação científica obrigou-o a separá-la completamente das outras formas da interpretação - a interpretação criadora -, em vez de reconhecer sem rodeios a indissolubilidade entre o entender e o interpretar em todas elas. Ele não queria admitir que as decisões complementares que o tradutor, o ator e o músico têm de encontrar, assim como as decisões práticas do juiz ou do teólogo (Seelsorger), nascem do entendimento e reconhecem totalmente o padrão do entendimento "correto". Considerando estas questões, eu mesmo falei de uma indistinção estética, que desempenha o papel decisivo em especial nas artes reprodutivas, desde que o modo de reprodução não se torne propriamente objeto (Gegenstand). No mesmo sentido, permanecem decisivos para o teólogo (Theologe) o momento da pregação e para o juiz e a justiça, o esforço pela solução justa. Isso mostra que o conceito de objeto (Objekt) e de objetividade (Objektivität) não basta onde não se trata da conquista de um objeto (Gegenstand) e da superação de uma resistência, mas da recuperação de uma participação no sentido. Mas isso nós chamamos entendimento.

Também não se pode querer renovar seriamente a antiga separação entre fatos e valores. Betti também não queria isso. Quando Betti, com Nicolai Hartmann, põe a cognoscibilidade dos valores em paralelo com a das "categorias" teóricas, ele admite completamente, com respeito a ambas, o momento subjetivo da perspectiva. Sem dúvida, quando ele defende a objetividade do conhecimento como critério, isso poderia ser para a pesquisa científica uma descrição adequada, que formula bem o processo de progressão e aproximação, que são a lei de andamento do trabalho científico. No entanto, quando estende a objetividade também ao nosso sentimento dos valores ${ }^{4}$, ele incorre, com tal paralelismo, em aporias insolúveis. O pesquisador de valores assume então o precário - para não dizer ridículo - papel de um juiz superior sobre os méritos e unilateralidades das formas de ethos vividas, e recorre ele próprio a uma espécie de super-ethos. Nicolai 
Hartmann chamou isso de valor do conjunto de valores (Wert der Wertfülle). Eu mesmo também fui educado por Nicolai Hartmann, mas nunca convencido de sua pesquisa dos valores que se acredita fenomenológica, empreendida por ele para exploração daquele céu de valores à luz do candeeiro de seu quarto, quando, entusiasmado, observou com seu telescópio não exatamente o verdadeiro céu estrelado. Na verdade, apesar de Scheler, Hartmann e Betti, com a idéia da pesquisa de valores, pareceu-me que foram atingidos os limites nos quais o ethos da ciência e de sua objetividade transforma-se no contra-ethos do teorizar e do afastar pela reflexão as obrigações práticas.

É muito instrutivo ver hoje em dia como uma geração mais jovem de filósofos e juristas italianos, que seguiu com simpatia os desenvolvimentos mais recentes do cenário alemão, vê as tensões, os problemas e as aporias nas quais os pensamentos do respeitado mestre Betti se enredam. Provavelmente, não é como se aí fosse dito apenas algo que não nos dissesse respeito. É antes nosso próprio assunto que está também em jogo. A herança de Hegel - as origens românticas do pensamento histórico que fez as Geisteswissenschaften alemãs tão grandiosas - está realmente em jogo em nossos dias. Não é apenas o velho descontentamento com a história de que Goethe já padecia. É antes uma crescente exigência de segurança que se expande por toda parte, possa ela ser satisfeita na crença do método da ciência, particularmente nas ciências sociais modernas, possa ela exigir o fortalecimento em uma ideologia que se alimenta da crítica de todas as ideologias. Mais uma vez pergunta uma geração mais nova como o jovem Heidegger perguntou depois da Primeira Guerra Mundial, tendo em vista o idealismo de formação neokantiano - o que esta tradição, que foi o orgulho de formação de uma época burguesa, ainda é realmente. Na época da tecnocracia e da burocracia, dos meios de comunicação de massa e da reprodutibilidade técnica, da literatura engajada e da antiarte, do pathos de emancipação e do desmoronamento da autoridade, parece um falso romantismo apelar a um consenso subjacente que possibilite a convivência dos homens. Talvez se reconheça que a eficácia das instituições sociais, assim como os valores mais fundamentais de nossa existência, não estão submetidos à própria racionalização científica. Mas postular um consenso sobre estas coisas parece ter origem antes em uma opção conservadora que em um discernimento filosoficamente fundado.

Não nego que existam aqui outras objeções, trazidas especialmente sob o lema da crítica da ideologia. O modelo originário hermenêutico é o diálogo, e 
este está sob a idéia condutora da obtenção de compreensão (Verständigung). Naturalmente isso não precisa levar sempre ao consenso. Pode ser também um intercâmbio compreensivo de razões e contra-razões. Mas, então, ainda se pressupõe também nesse caso um consenso subjacente. Pois o resultado da compreensão só é positivo se, através dele, a superação de oposições, a intermediação e o compromisso possam começar a se desenvolver.

Ora, é certo que há barreiras ideológicas que alcançam mesmo o vocabulário do intercâmbio de opiniões diário, e é igualmente certo que a disposição para a conversação pode ser paralisada sob a pressão de tais barreiras. Mas, na verdade, nem mesmo teóricos da crítica da ideologia contestam o fato de que entre seres racionais, por fim, apenas o intercâmbio racional pode ser o caminho humano da solução dos problemas entre os homens.

Os conceitos de tradição, autoridade, continuidade, etc. não devem ser sobrecarregados com opções “contrafáticas”. Eles formulam o fato de que nossa razão e racionalidade têm uma limitação essencial. Quando não reconhece seus limites, ela se perde na declamação abstrata. Não precisa ser repetido aqui o que se obteve de esclarecimento através da discussão frutífera entre a hermenêutica e a crítica da ideologia em ambos os lados. Há, creio eu, uma concordância de que nunca se pode separar razão de crítica. A única constituição fundamental do ser humano é a de não se prender a meras maneiras instintivas de reagir, mas poder pensar possibilidades e ser apto a escolher no comportamento prático entre possibilidades. Mas escolher significa sempre exercitar a crítica: decidir, preferir e preterir. Naturalmente, as condições da práxis racional e da racionalidade prática têm de ser sempre afirmadas. Ninguém começa a partir do ponto zero da ausência de preconceitos e da imparcialidade. Nós estamos em um processo, e isso a que se chama hoje socialização é uma fase desse processo. A uniformização do singular na sociedade apresenta um curso complexo, no qual, pouco a pouco, com maior ou menor radicalidade, heranças, hábitos, costumes e modelos inculcados de comportamento são questionados e submetidos a uma rejeição e apropriação racionais, ainda que não necessariamente entregues a uma reflexão emancipatória.

É, portanto, a constituição fundamental e universal, ontológica ou antropológica do homem que uma hermenêutica filosófica tem de levar em consideração contra conceitos abstratos de razão e reflexão. Tentei fazer isso no modelo do diálogo e, como penso, procurei indicar no retorno aos fenômenos originais da existência social do homem. Que, com isso, se vise a uma dimensão de exercí- 
cio da razão muito mais original do que aquela da ciência e de sua objetividade, que só então é construída sobre a mesma, é uma circunstância que me permite, em grande parte, estar de acordo com as tentativas de justificação pelo pensamento empreendidas por Emilio Betti - e esta circunstância transforma em dever filosófico o ir além e o retornar aquém dela.

\section{Notas}

1. Gadamer, Hans-Georg. Verdad y metodo.Trad. A.A. Aparicio e R. Agapito. Salamanca, Ediciones Sígueme, $4^{\mathrm{a}}$ ed., 1991, p. 600.

2. Emilio Betti escreve às páginas 260 e seguintes de sua Teoria generale della interpretazione (Milão, Giuffrè Editore, $2^{\mathrm{a}}$ ed., 1990): "Estes dois termos do processo (interpretativo), sujeito e objeto, são os mesmos dois termos que se encontram em todo processo cognitivo; mas aqui eles aparecem caracterizados por qualificações particulares, dado que não se trata de um objeto qualquer, mas precisamente de objetivações do espírito, e que aqui a tarefa do sujeito consiste em tornar a conhecer, em reconhecer naquelas objetivações, o pensamento animador, em repensar a concepção do autor ou em evocar a intuição que aí se revela. Aqui, em suma, o conhecer é um reconhecer e um identificar o outro espírito que, através das formas da sua objetivação, fala ao espírito pensante que se sente a ele assemelhado na humanidade comum. É um reconduzir e reunir aquelas formas na interioridade que as gerou e da qual foram separadas, um interiorizá-las, transpondose todavia o conteúdo em uma subjetividade diversa daquela sua originária. Dá-se assim uma inversão do processo inventivo no processo interpretativo. Uma inversão pela qual no iter hermenêutico o intérprete deve percorrer de novo, em sentido retrospectivo, o iter genético e fazer, em si próprio, a reflexão desse percurso".

3. O objetivo de Emilio Betti com sua Teoria generale della interpretazione é construir uma teoria hermenêutica aplicável a toda e qualquer interpretação. As diversas espécies de interpretação são por ele sistematizadas e ordenadas em três grupos distintos, conforme a função que desempenham. São eles: 1) interpretação com função meramente reconhecedora (interpretações filológica, histórica e técnica); 2) interpretação com função reprodutiva (interpretações dramática, musical e tradução); 3) interpretação com função normativa (interpretações jurídica, psicológica e teológica). As interpretações com função meramente reconhecedora visam a reconhecer as manifestações de pensamento objetivadas no material interpretado. 
Nesse tipo de interpretação o entendimento é um fim em si mesmo. Nas interpretações com função reprodutiva e normativa o objetivo não é o mero entender, mas, respectivamente, o fazer entender e o entender com o fim de regular condutas. Esses dois tipos de interpretação pressupõem o entendimento como primeiro momento, mas não se esgotam nele. Segundo Emilio Betti, nesses dois casos é necessário um segundo momento, capaz de adaptar o entendimento inicial à função que a interpretação deve desempenhar. Exemplo bastante ilustrativo da diferença entre a interpretação com função meramente reconhecedora e a interpretação com função normativa é dado por Betti quando compara as atividades do historiador e do aplicador do direito - o que é objeto da crítica de Gadamer não apenas no presente texto, mas também no prefácio a $2^{a}$ edição de Wahrheit und Methode. Ele escreve: "O ponto principal na diferença entre interpretação histórica e interpretação jurídica é que, na primeira, se trata unicamente de evocar em sua autonomia, de reconstruir em sua totalidade, de integrar em sua coerência originária o sentido - nela encerrado - da forma representativa e com ela o pensamento que expressa; pelo contrário, na interpretação jurídica de um ordenamento vigente não podemos nos ater a evocar o sentido originário da norma, mas se deve ir um passo além, porque a norma, longe de esgotar-se em sua primeira formulação, tem vigor atual com relação ao ordenamento de que é parte integrante e acha-se destinada a permanecer e a transformar-se na vida social, a cuja disciplina deve servir. Aqui, portanto, o intérprete não termina de cumprir seu objetivo quando reconstrói a idéia originária da fórmula legislativa - coisa que antes de tudo deve fazer -, mas deve, depois disso, pôr em acordo aquela idéia com a atualidade presente infundindo-lhe a vida que essa contém, pois é justamente a ela que a valoração normativa deve ser referida" (La interpretación de las leyes y de los actos jurídicos. Trad. J.L. Mozos da $2^{\mathrm{a}}$ edição italiana. Madri, Editorial Revista de Derecho Privado, p. 43).

4. Em um texto de 1949, publicado posteriormente como prolegômenos a sua Teoria generale della interpretazione, Emilio Betti trata da posição do espírito com respeito à objetividade. Nesse texto - que segue a filosofia dos valores de Nicolai Hartmann - ele distingue dois níveis distintos de objetividade. Usando terminologia kantiana, escreve que existe objetividade não apenas no nível do fenômeno - objetividade real -, mas também com relação àquilo que Kant chamou "condições da sua possibilidade”. Nesse segundo nível há o que Betti chamou de objetividade ideal. É nele que se dá a objetividade dos valores. Betti escreve: "Os valores éticos ou estéticos, da mesma maneira que as categorias lógicas, pertencem a uma segunda dimensão de objetividade, que não é aquela meramente fenomênica, mas que, assim como essa, distingue-se da subjetividade da consciência: uma objetividade que, configurando um modo de ser não fenomênico da espiritualidade, pode bem qualificar-se ideal" (Teoria generale della interpretazione. Milão, Giuffrè Editore, $2^{\mathrm{a}}$ ed., 1990, p. 11). 